\title{
PENGARUH HARD SKILL DAN SOFT SKILL TERHADAP SELF EFFICACY MAHASISWA
}

\author{
Windarini Cahyadiana \\ Sekolah Tinggi Informatika dan Komputer Indonesia (STIKI) Malang \\ Email : windarini@stiki.ac.id
}

\begin{abstract}
ABSTRAK. Tujuan dari penelitian ini adalah untuk mengetahui seberapa besar pengaruh hard skill dan soft skill dalam membentuk self efficacy (keyakinan diri) mahasiswa. Karena dua kecakapan ini merupakan kecakapan yang mampu menjadikan individu yang memilikinya, merasa yakin akan kemampuannya dalam melakukan suatu aktifitas dan mencapai hasil seperti yang diharapkan. Penelitian ini bisa digolongkan dalam classroom action research. Penulis melakukan pengamatan selama proses belajar mengajar, dan juga menggunakan angket untuk mengetahui pendapat para responden. Berdasarkan hasil analisis, ternyata self management, merupakan variabel yang berperan paling besar dalam membentuk self efficacy individu. Memiliki self management, berarti mampu mengelola diri dan hubungan dengan sesama.
\end{abstract}

Kata kunci : Mahasiswa ; Hard Skill ; Soft Skill ; Self Efficacy.

ABSTRACT. The purpose of this research is to determine how much influence hardskills and softskills to shaping self efficacy of university student. Because these two skills, can make individuals who have it, feel confident to do an activity and get the results as expected. This research can be classified in classroom action research. The author made observations during the teaching and learning process, and also used a questionnaire to find out the opinions of the respondents. And the results, self management is the variable that plays the biggest role in shaping individual self efficacy. Having self management, means being able to manage themselves and relationships with others.

Keywords : University student, Hard Skill, Soft Skill, Self Efficacy 


\section{PENDAHULUAN}

\subsection{Latar Belakang}

Setiap individu, memiliki dua hakekat, yaitu sebagai makhluk individu dan makhluk sosial. Sebagai makhluk individu, maka setiap individu memiliki cipta, rasa dan karsa. Sedangkan sebagai makhluk sosial, membuat setiap individu tidak akan pernah bisa hidup sendiri, melainkan akan selalu membutuhkan relasi dengan sesamanya.

Di era yang sangat kompetitif ini, maka keberhasilan seorang individu tidak hanya ditentukan oleh kemampuan akademisnya saja (hard skill), namun juga ditentukan oleh soft skill, sebuah kecakapan dibutuhkan agar seorang individu mampu mengelola emosi diri sendiri (intrapersonal skill) dan mampu mengelola emosi saat membangun relasi dengan sesamanya (interpersonal skill). Sebuah penelitian yang dilakukan di Harvard University, menyatakan bahwa kesuksesan seseorang tidak semata-mata ditentukan oleh kemampuan teknisnya (hard skill) saja, tetapi juga kemampuan individu dalam mengontrol emosi (softskill).

Mahasiswa, merupakan sumber daya manusia yang dihasilkan oleh Perguruan Tinggi. Mahasiswa dengan potensi yang tinggi, akan berpeluang lebih besar dalam mencapai prestasi akademiknya. Jika mahasiswa mengoptimalkan seluruh potensi yang dimilikinya, maka kemungkinan besar mampu berprestasi dibidang akademis. Sehingga mahasiswa bisa dikatakan memiliki hard skill, yaitu kemampuan akademis sesuai disiplin ilmu yang ditekuninya. Namun agar menjadi sumber daya yang unggul, mahasiswa juga diharapkan memiliki softskill, berupa intrapersonal skill dan interpersonal skill, sehingga mahasiswa menjadi individu yang memiliki kemampuan holistik, karena mahasiswa akan menjadi individu yang cerdas dalam berpikir, dan juga cerdas dalam bertindak maupun bersikap. Memiliki hard skill dan soft skill, akan membuat mahasiswa menjadi sumber daya manusia yang utuh, yang memiliki kecakapan / ketrampilan holistik, karena memiliki : 1) kemampuan akademis, 2) kemampuan mengelola diri, 3) kemampuan menjalin relasi harmonis dengan sesamanya, dan 4) kemampuan melakukan perubahan. Dengan beragam kemampuan yang dimiliki tersebut, maka mahasiswa akan memiliki self efficacy, yaitu keyakinan diri akan kemampuan yang dimilikinya, serta memiliki keyakinan akan kesanggupan melakukan sebuah tanggung jawab. Sehingga pada akhirnya, mahasiswa diharapkan memiliki keyakinan dan kesanggupan saat memasuki dunia kerja dan berkompetisi.

Hard skill akan membuat seorang individu memiliki kompetensi di bidang keilmuannya. Sedangkan soft skill akan membuat mahasiswa kemampuan mengelola emosi diri dan mengelola emosi terhadap sesamanya. Kedua kecakapan memiliki peran cukup besar terhadap kesuksesan mereka di masa akan datang. ini Jika mahasiswa dibekali dengan hard skill dan soft skills yang cukup, bahkan kedua kecakapan tersebut telah menjadi bagian dari hidup dan aktifitas mereka, maka peluang untuk menjadi sukses menjadi semakin besar.

Jadi, hard skill merupakan kemampuan yang berifat kognitif, sedangkan soft skills merupakan kemampuan yang bersifat afektif, yang membuat individu yang memiliki kedua kecakapan tersebut akan mampu beradaptasi dengan lingkungannya. Setiap individu bisa memiliki hard skill yang berbeda, namun setiap individu dituntut memiliki soft skill, apapun profesinya. Sehingga, idealnya, hard skill dan soft skills, adalah dua kecakapan yang harus 
dimiliki oleh setiap mahasiswa, agar mereka mampu menyelesaikan studinya dengan hasil seperti yang diharapkan, seeta mendapatkan kesuksesan dalam dunia.

Melalui penelitian ini, penulis memberikan pernyataan berupa angket kepada responden (mahasiswa) tentang beberapa bentuk softskill yang harus mereka asah secara terus menerus, agar mereka memiliki keyakinan diri, bahwa dirinya sanggup melakukan suatu aktifitas dan memperoleh hasil seperti yang diharapkan.

\subsection{Rumusan Masalah}

Berdasarkan uraian tersebut diatas, maka beberapa pertanyaan yang dimunculkan dalam penelitian ini adalah :

1. Apakah terdapat pengaruh secara parsial dari Hard Skill dan Soft Skill terhadap Self Efficacy mahasiswa?

2. Apakah terdapat pengaruh secara simultan dari Hard Skill dan Soft Skill terhadap Self Efficacy mahasiswa?

3. Diantara semua variabel bebas yang ada, yaitu 1) Hard Skill (X1 Intellectual Skill) dan Soft Skill (X2 Self Awareness (X2.1), Self Management (X2.2), Motivation (X2.3), Emphaty (X2.4), dan Relationship Management (X2.5), variabel manakah yang paling berperan dalam membentuk Self Efficacy mahasiswa?

\subsection{Tujuan Penelitian}

Berdasarkan rumusan masalah seperti tersebut diatas, maka tujuan dari penelitian ini, adalah :

1. Untuk mengetahui pengaruh secara parsial dari Hard Skill dan Soft Skill terhadap Self Efficacy mahasiswa ?

2. Untuk mengetahui pengaruh secara simultan dari Hard Skill dan Soft Skill terhadap Self Efficacy mahasiswa?
3. Untuk mengetahui variabel yang paling dominan dalam membentuk Self Afficacy mahasiswa.

\section{METODE PENELITIAN}

\subsection{Jenis Penelitian}

Penelitian mengambil lokasi di STIKI Malang, karena yang menjadi objek peneitian adalah mahasiswa STIKI Malang.

\subsection{Subjek Penelitian}

Dalam penelitian ini, responden adalah mahasiswa STIKI Malang, program studi Manajemen Informatika dan Sistem Informasi.

\subsection{Teknik Pengumpulan Data}

Pengumpulan data dilakukan dengan dua cara, yaitu : 1) Pembagian angket, dan 2) Pengamatan secara langsung terhadap responden selama proses belajar mengajar pada semester genap 2018/2019.

\subsection{Teknik Analisis Data}

Dari data yang diperoleh, kemudian dilakukan beberapa pengujian, yaitu :

a) Uji Validitas

Untuk mengukur sampai sejauh mana ketepatan instrumen penelitian, sehingga mampu memberi informasi yang akurat.

b) Uji Reliabilitas

Untuk mengetahui tingkat kehandalan instrumen yang digunakan dalam penelitian, atau kepercayaan terhadap suatu hasil pengukuran.

c) Uji Asumsi Klasik, berupa Uji Normalitas dan Uji Multikolinieritas Untuk mengetahui apakah data yang diperoleh dapat dianggap mewakili populasi, dan tidak ada korelasi kuat antara dua variabel bebas atau lebih.

d) Uji Signifikansi 
Untuk mengetahui dan membuktikar apakah variabel bebas (independer variable) memiliki pengaruh signifika atau tidak terhadap variabel teriki (dependent variable).

\section{HASIL DAN PEMBAHASAN \\ 3.1. Uji Validitas}

Jika korelasi antar item dengan skc SELF total lebih dari 0,3 maka instrume NESS dikatakan "Valid" namun jika kuran dari 0,3 maka instrumen dikatakan "Tida Valid". Hasil dari pengujian Validita: MANAGEdiperoleh tabel sebagai berikut :
Tabel 1 Correlations

\begin{tabular}{|c|c|c|c|c|c|c|c|c|}
\hline & & $\begin{array}{l}\text { IN- } \\
\text { TEL- } \\
\text { LEC- } \\
\text { TUAL } \\
\text { SKILL }\end{array}$ & $\begin{array}{c}\text { SELF } \\
\text { AWARE- } \\
\text { NESS }\end{array}$ & $\begin{array}{c}\text { SELF } \\
\text { MANA- } \\
\text { GE- } \\
\text { MENT }\end{array}$ & $\begin{array}{l}\text { MO-TI- } \\
\text { VA-TION }\end{array}$ & $\begin{array}{l}\text { EM- } \\
\text { PHATY }\end{array}$ & $\begin{array}{c}\text { RE- } \\
\text { LA- } \\
\text { TIONS } \\
\text { HIP } \\
\text { MANA } \\
\text { GEME } \\
\text { NT }\end{array}$ & $\begin{array}{l}\text { TO- } \\
\text { TAL } \\
\mathbf{X}\end{array}$ \\
\hline \multirow[t]{3}{*}{$\begin{array}{l}\text { INTELLEC- } \\
\text { TUAL SKILL }\end{array}$} & $\begin{array}{l}\text { Pearson } \\
\text { Correla- } \\
\text { tion }\end{array}$ & 1 &, 059 &, 115 &,- 064 &, 043 &, 053 &, $365^{* * 1}$ \\
\hline & & & ,683 & ,428 & ,661 & ,769 &, 717 &, 009 \\
\hline & $\mathrm{N}$ & 50 & 50 & 50 & 50 & 50 & 50 & 50 \\
\hline \multirow[t]{3}{*}{$\begin{array}{l}\text { SELF } \\
\text { AWARE- } \\
\text { NESS }\end{array}$} & $\begin{array}{l}\text { Pearson } \\
\text { Correla- } \\
\text { tion }\end{array}$ & ,059 & 1 &, 154 &, 118 & ,254 &, 257 &, $503^{* *}$ \\
\hline & $\begin{array}{l}\text { Sig. (2- } \\
\text { tailed) }\end{array}$ & ,683 & & ,286 & ,413 &, 075 &, 072 & ,000 \\
\hline & $\mathrm{N}$ & 50 & 50 & 50 & 50 & 50 & 50 & 50 \\
\hline \multirow[t]{3}{*}{$\begin{array}{l}\text { SELF } \\
\text { MANAGE- } \\
\text { MENT }\end{array}$} & $\begin{array}{l}\text { Pearson } \\
\text { Correla- } \\
\text { tion }\end{array}$ &, 115 &, 154 & 1 &, $357^{*}$ &, $468^{* *}$ & ,217 &, $646^{* *}$ \\
\hline & $\begin{array}{l}\text { Sig. (2- } \\
\text { tailed) }\end{array}$ & , 428 & ,286 & &, 011 & ,001 & 130 &, 000 \\
\hline & $\mathrm{N}$ & 50 & 50 & 50 & 50 & 50 & 50 & 50 \\
\hline \multirow{4}{*}{$\begin{array}{l}\text { MOTIVA- } \\
\text { TION }\end{array}$} & Pearson &,- 064 &, 118 & $357^{*}$ & 1 &, $298^{*}$ &, $464^{* *}$ &, $649^{* *}$ \\
\hline & & & & & & & & \\
\hline & $\begin{array}{l}\text { Sig. (2- } \\
\text { tailed) }\end{array}$ & ,661 & ,413 & ,011 & & ,036 & ,001 &, 000 \\
\hline & $\mathrm{N}$ & 50 & 50 & 50 & 50 & 50 & 50 & 50 \\
\hline \multirow[t]{4}{*}{ EMPHATY } & Pearson & ,043 &, 254 &, $468^{* *}$ &, $298^{*}$ & 1 &, $348^{*}$ &, $655^{* *}$ \\
\hline & & & & & & & & \\
\hline & $\begin{array}{l}\text { Sig. (2- } \\
\text { tailed) }\end{array}$ & ,769 & ,075 & ,001 & ,036 & & ,013 &, 000 \\
\hline & $\mathrm{N}$ & 50 & 50 & 50 & 50 & 50 & 50 & 50 \\
\hline \multirow{3}{*}{$\begin{array}{l}\text { RELA- } \\
\text { TIONSHIP } \\
\text { MANAGE- } \\
\text { MENT }\end{array}$} & Pearson &, 053 & ,257 &, 217 &, $464^{* *}$ &, $348^{*}$ & 1 &, $679^{* * 2}$ \\
\hline & $\begin{array}{l}\text { Correla- } \\
\text { tion } \\
\text { Sig. (2- } \\
\text { tailed) }\end{array}$ & ,717 & ,072 & ,130 & ,001, & ,013 & &, 000 \\
\hline & $\mathrm{N}$ & 50 & 50 & 50 & 50 & 50 & 50 & 50 \\
\hline \multirow[t]{3}{*}{ TOTAL X } & $\begin{array}{l}\text { Pearson } \\
\text { Correla- } \\
\text { tion }\end{array}$ &, $365^{* *}$ &, $503^{* *}$ &, $646^{* *}$ &, $649^{* *}$ &, $655^{* *}$ &, $679^{* 3}$ & 1 \\
\hline & $\begin{array}{l}\text { Sig. (2- } \\
\text { tailed) }\end{array}$ & ,009 & ,000 & ,000 & ,000 & ,000 & ,000 & \\
\hline & $\mathrm{N}$ & 50 & 50 & 50 & 50 & 50 & 50 & 50 \\
\hline
\end{tabular}

Berdasarkan tabel 1, pada kolom Total X, diketahui bahwa variabel X1 (Hard SkillIntellectual Skill) dan variabel X2 (Soft Skill-Self Awareness, Self Management, Motivation, Emphaty, dan Relationship Management) semuanya memiliki 
koefisien lebih besar dari 0,3. Dengan demikian, dapat dikatakan bahwa instrumen yang digunakan adalah instrumen yang valid.

\subsection{Uji Reliabilitas}

Uji reliabilitas dilakukan dengan menggunakan metode Alpha-Cronbach's, untuk menguji apakah instrumen yang digunakan dalam penelitian ini handal (reliabel) atau tidak. Dikatakan handal, jika memiliki koefisien reliabilitas atau alpha lebih besar atau sama dengan 0,6.

Dari hasil pengujian Reliabilitas, diperoleh tabel sebagai berikut :

\section{Tabel 2}

Reliability Statistics

\begin{tabular}{cc}
\hline Cronbach's Alpha & N of Items \\
\hline, 601 & 6 \\
\hline
\end{tabular}

\begin{tabular}{lcccc}
\hline & Item-Total Statistics & \\
\hline & $\begin{array}{c}\text { Scale } \\
\text { Item if } \\
\text { Deleted }\end{array}$ & $\begin{array}{c}\text { Scale } \\
\text { Variance } \\
\text { if Item } \\
\text { Deleted }\end{array}$ & $\begin{array}{c}\text { Correc- } \\
\text { ted Item- } \\
\text { Total } \\
\text { Corre- } \\
\text { lation }\end{array}$ & $\begin{array}{c}\text { Cron- } \\
\text { bach's } \\
\text { Alpha if } \\
\text { Item } \\
\text { Deleted }\end{array}$ \\
\hline $\begin{array}{l}\text { INTELLECTUAL } \\
\text { SKILL }\end{array}$ & 18,7000 & 2,173 &, 056 &, 673 \\
\hline $\begin{array}{l}\text { SELF } \\
\text { AWARENESS }\end{array}$ & 18,5200 & 2,010 &, 266 &, 582 \\
\hline $\begin{array}{l}\text { SELF } \\
\text { MANAGEMENT }\end{array}$ & 18,5400 & 1,804 &, 439 &, 514 \\
\hline MOTIVATION & 18,6400 & 1,704 &, 388 &, 532 \\
\hline EMPHATY & 18,4800 & 1,847 &, 477 &, 507 \\
\hline $\begin{array}{l}\text { RELATIONSHIP } \\
\text { MANAGEMENT }\end{array}$ & 18,6200 & 1,710 &, 461 &, 500 \\
\hline
\end{tabular}

Berdasarkan tabel 2 (Reliability Statistics), diketahui Cronbach's Alpha sebesar 0,601.

Sehingga dapat dikatakan, instrumen yang digunakan adalah instrumen yang "Reliabel / Handal"

\subsection{Uji Asumsi Klasik}

\subsubsection{Uji Normalitas}

Dari hasil input data, diperoleh gambar Histogram sebagai berikut :
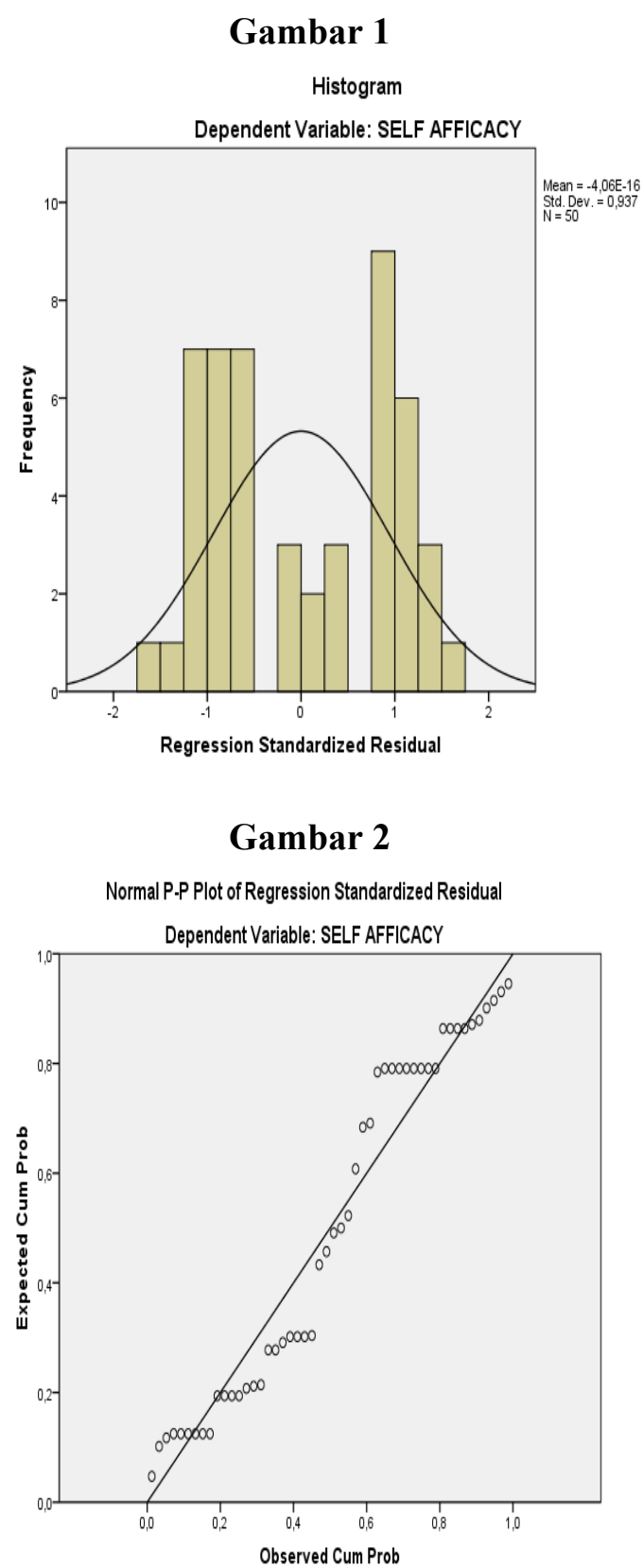

Berdasarkan gambar 1 (gambar histogram), terlihat gambar Histogram berupa kurva normal yang membentuk pola simetris. Berdasarkan gambar 2 
(standardized Residual), terlihat titik-titik residual cenderung menyebar diantara garis diagonal. Berarti, residual menyebar normal.

Dengan demikian dapat dikatakan, data yang digunakan telah mewakili populasi.

\subsubsection{Uji Multikolinieritas}

Dari hasil input data, diperoleh tabel sebagai berikut :

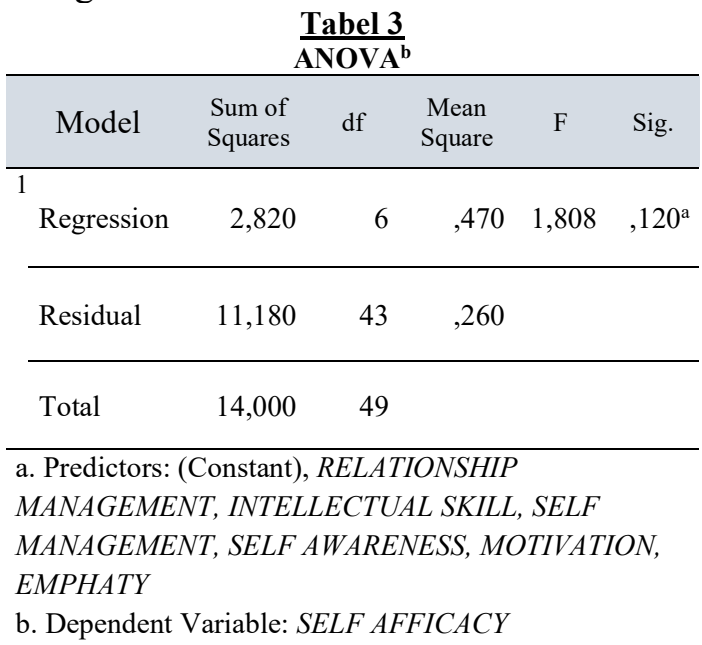

Tabel 4 Coefficients $^{\mathrm{a}}$

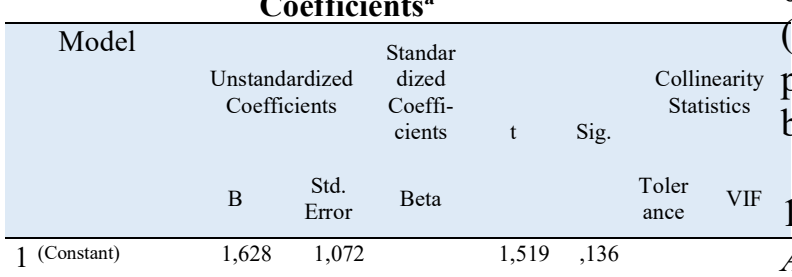

$\begin{array}{llllllll}\begin{array}{l}\text { INTELLECTUAL } \\ \text { SKILL }\end{array} & , 147 & , 150 & , 136 & , 981 & , 332 & , 966 & 1,035\end{array}$

\begin{tabular}{lllllllll} 
SKILL & & & & & & & & \\
\hline & & & & & & & & \\
SELF &,- 158 &, 183 &,- 124 &,- 863 &, 393 &, 900 & 1,111 \\
AWARENESS & & & & &
\end{tabular}

\begin{tabular}{llllllll} 
AWARENESS &,- 158 &, 183 &,- 124 &,- 863 &, 393 &, 900 & 1,111 \\
\hline
\end{tabular}

$\begin{array}{llllllll}\begin{array}{l}\text { SELF } \\ \text { MANAGEMENT }\end{array} & , 404 & , 200 & , 326 & 2,021 & , 049 & , 713 & 1,402\end{array}$

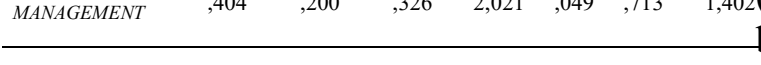

$\begin{array}{llllllll}\text { MOTIVATION } & \text {, 183 } & \text {, 168 } & \text {, 178 } & 1,093 & \text {,700 } & 1,428\end{array}$

\begin{tabular}{llllllll}
\hline EMPHATY &,- 226 &, 225 &,- 164 & $-1,004$ &, 321 &, 698 & 1,432
\end{tabular}

\begin{tabular}{lllllllll} 
& & & & & & & \\
\hline RELATIONSHIP & 139 &, 184 &, 123 &, 758 &, 453 &, 706 & 1,417 \\
MANAGEMENT &, 139 & & & & & & &
\end{tabular}

a. Dependent Variable: SELF AFFICACY

Berdasarkan tabel 4 (Coefficients ${ }^{\text {a)} \text {, }}$ diketahui variabel X1 (Hard Skill Intellectual Skill) dan X2 (Soft Skill - Self Awareness (X2.1), Self Management (X2.2), Motivation (X2.3), Emphaty (X2.4), dan Relationship Management (X2.5) ) memiliki nilai VIF (Variance Inflation Factor) kurang dari 10, dan nilai Tolerance lebih besar dari 0,1 sehingga dapat dikatakan tidak terjadi Multikolinieritas, artinya, tidak ada korelasi yang kuat antara dua variabel bebas atau lebih

\subsection{Uji Signifikan \\ 3.4.1. Pengaruh Secara Parsial}

Dengan menggunakan tingkat kepercayaan 0,95 dan tingkat kesalahan (alpha) 0,05, maka, berdasarkan tabel 4 (Coefficients $^{\text {a) }}$, diketahui nilai Probalitas (Sig) dari Konstanta 0,136 ; Intellectual Skill (X1) 0,332 ; Self Awareness (X2.1) 0,393 ; Self Management (X2.2) 0,049; Motivation (X2.3) 0,281; Emphaty (X2.4) 0,321 ; Relationship Management (X2.5) 0,453 . Artinya, lebih besar dari alpha $(0,05)$. Sedangkan nilai Probalitas (Sig) pada Self Management (X2.6) 0,049, yang berarti lebih kecil dari alpha $(0,05)$

Sedangkan nilai t pada Konstanta 1,519 ; Intellectual Skill 0,981; Self Awareness 0,863 ; Motivation 1,093 ; , 1,004 Emphaty Relationship Management 0,758. Artinya, nilai thitung lebih kecil dari t tabel (2,016692). Dan nilai t pada variabel Self Management .2) 2,021, yang berarti t hitung lebih besar dari $t$ tabel $(2,016692)$.

Jadi, secara parsial, Hard Skill (X1-Intellectual Skill), dan Soft Skill (X2Self Awareness (X2.1), Motivation (X2.3), Emphaty (X2.4), dan Relationship Management (X2.5), secara parsial berpengaruh tidak signifikan terhadap Self Afficacy. Tetapi, secara parsial, Self Management (X2.2), berpengaruh signifikan terhadap Self Afficacy. 


\subsubsection{Pengaruh Secara Simultan} Berdasarkan tabel 3 (ANOVA ${ }^{\mathbf{b}}$ ), diketahui $\mathrm{F}$ hitung sebesar 1,808; probabilitas sebesar 0,120 , dan alpha 0,05 . Berarti F hitung $<$ F tabel $(2,318498)$ atau probabilitas $>$ alpha

Sehingga, secara simultan, Intellectual Skill, Self Awareness, Motivation, Emphaty, dan Relationship Management berpengaruh tidak signifikan terhadap Self Afficacy.

\subsubsection{Pengaruh Paling Dominan}

Berdasarkan hasil analisis data, diketahui bahwa dari semua variabel bebas yang ada, yaitu : 1) Hard Skill (X1 - Intellectual Skill) dan Soft Skill (X2 Self Awareness (X2.1), Self Management (X2.2), Motivation (X2.3), Emphaty (X2.4), dan Relationship Management (X2.5), yang memiliki pengaruh paling dominan dalam membentuk Self Afficacy mahasiswa adalah : Self Management.

\section{KESIMPULAN DAN SARAN Kesimpulan}

Berdasarkan analisis hasil dan pembahasan, diperoleh kesimpulan sebagai berikut : Hard Skill (Intellectual Skill) dan Soft Skill (Self Awareness, Self Management, Motivation, Emphaty, dan Relationship Management), memiliki peranan dalam membentuk Self Afficacy mahasiswa. Diantara semua variabel bebas yang digunakan, Self Management yang memiliki pengaruh paling dominan dalam mewujudkan Self Afficacy mahasiswa.

$$
\text { Dengan memiliki Self }
$$

Management, mahasiswa akan mampu mengelola dirinya dengan baik dan benar, sehingga dia akan menjadi individu yang memiliki keyakinan mampu melakukan suatu aktifitas dengan baik, mampu memperoleh hasil seperti yang diharapkan, mampu mengelola emosinya dengan baik, mampu bertanggung jawab dan memberi pertanggungan jawab, dan mampu mengelola hubungan baik dengan sesamanya.

\section{Saran}

Perlunya menanamkan kesadaran kepada mahasiswa secara terus menerus, dari hari ke hari, dan diselipkan disetiap tatap muka pembelajaran, tentang pentingnya memiliki self management, dan juga senantiasa mendorong mahasiswa untuk berperan aktif dalam berbagai aktifitas kampus, sehingga self management benarbenar menjadi bagian dari kehidupan mahasiswa.

\section{DAFTAR PUSTAKA}

\section{Dari Buku :}

Goleman, Daniel. 2002. Kecerdasan Emosional.

Goleman, Daniel. 2006. Social Intelegence. Jakarta: Gramedia Pustaka Utama

I Made S.Utama, dkk. (2010). Konsep Pengembangan Panduan Evaluasi Pengembangan Soft skills Mahasiswa Melalui Proses Pembelajaran di Universitas Udayana.

Bandura, Albert. 1993. Perceived SelfEfficacy in Cognitive Development and Functioning.

Bandura, Albert. 1997. Self-Efficacy the Exercise of Control. New York: W. H. Freeman and Company.

\section{Dari Jurnal :}

Hadi Warsito. Hubungan Antara Self Efficacy Dengan Penyesuaian Akademik Dan Prestasi Akademik ( Studi Pada Mahasiswa FIP Universitas Negeri Surabaya). Jurnal Ilmiah Ilmu Pendidikan Volume IX No.1 April 2009.

Deta Shinta Kusuma Wardani. Pengaruh 
Pelatihan Komunikasi Efektif Untuk Meningkatkan Efikasi Diri Mahasiswa. Jurnal Psikologi Pendidikan dan Perkembangan Vol. 1 No. 02, Juni 2012 Fakultas Psikologi Universitas Airlangga. Surabaya

Ni Made Ferra Sarah. Deviyanthi dan Putu Nugrahaeni Widiasavitri. 2016. Hubungan Antara Self-Efficacy dengan Kecemasan Komunikasi dalam Mempresentasikan Tugas di Depan Kelas. Jurnal Psikologi Udayana 2016, Vol. 3, No. 2, 342353.

Novia Lucas. Cahyadi Lie, Noviaty

Kresna Darmasetiawan. Pengaruh Soft Skill Terhadap Kesiapan Kerja Menghadapi Masyarakat Ekonomi ASEAN pada Mahasiswa S1 Fakultas Bisnis Ekonomika, Univ. Surabaya. Jurnal Ilmiah Mahasiswa Universitas Surabaya. Vol.6 No.2 (2017).

Alfaiz, Zulfikar, Darma Yulia. Efikasi

Diri Sebagai Faktor Prediksi

Kesiapan Mahasiswa Dalam Mengerjakan Tugas Kuliah. Jurnal Ilmu Pendidikan, Vol. 2 No. 2 , Desember 2017: 119-124.

Dewi Khrisna Sawitri, Wiwin Priana.

Efektifitas Kepuasan Pelatihan Soft Skill Terhadap Sikap Dan Self Esteem Mahasiswa Prodi Ekonomi Pembangunan UPN Jatim. (Artikel )
Efficacy_Sebagai_Atribut_Psikologi

_Dalam_Kesiapan_Karir_Mahasiswa

_Pada_Tingkat_Perguruan_Tinggi

https://www.researchgate.net/publication/ 307093334 SELF CONCEPT AND

SELF_EFFICACY_AS_A_GROUND_POINTS IN_A_SOCIAL_ACTIVITIES_AN_ANALYSIS _OF_PSYCHOLOGY_PERSPECTIVE_A_SOCI AL_COGNITIVE_THEORY

\section{Dari Internet :}

Prastiwi, W. 2011. Pengembangan Soft

Skill, Hard Skill dan Life Skill Peserta

Didik Dalam Menghadapi Era

Globalisasi.http://www.infodikdas.com

https://www.researchgate.net/publication/ 326674940 Peranan Self- 